\title{
Mapeamento de iniciativas brasileiras que fomentam a entrada de mulheres na Computação
}

\author{
Maria Augusta S. N. Nunes ${ }^{1,2,4}$, Carolina S. Louzada ${ }^{1,4}$, Edilayne M. Salgueiro, ${ }^{1,4}$, \\ Beatriz T. Andrade ${ }^{1,4}$, Patrícia S. de Lima ${ }^{3,4}$ Raquel M. C. T. Figueiredo ${ }^{2,4}$ \\ ${ }_{1}$ DCOMP- Universidade Federal de Sergipe/UFS - São Cristóvão- SE \\ ${ }_{2}$ PROCC -Universidade Federal de Sergipe/UFS -São Cristóvão- SE \\ ${ }_{3}$ Escola Estadual Atheneu Sergipense -Aracaju - SE \\ ${ }_{4}$ Projeto meninasnacomputacao.ufs.br -Aracaju - SE \\ gutanunes@gmail.com, carolina.louzada@hotmail.com, edilayne@ufs.br, \\ beatriz@ufs.br, paslima@globo.com, raquelmctf@gmail.com
}

\begin{abstract}
This paper provides an overview of Brazilian initiatives that promote women into the computing area. The methodology used was based on Systematic Mapping. After analyzing the data we concluded that despite the low representation of women in the computing area, there is currently a significant number of Brazilian initiatives that encourage the migration of women in computing.
\end{abstract}

Resumo. Esse artigo tem como objetivo obter um panorama das iniciativas brasileiras que fomentam a entrada de mulheres da área da Computação. A metodologia utilizada foi baseada no processo do Mapeamento Sistemático. Após a análise dos dados concluiu-se que apesar da baixa representatividade das mulheres, há atualmente uma significativa quantidade de iniciativas brasileiras que fomentam a entrada destas na Computação.

\section{Introdução}

De acordo com [Lima 2013], as mudanças culturais pelas quais a sociedade continuamente passa mudam a forma como as mulheres se veem e são vistas com relação à escolha das carreiras a seguir. Entretanto, apesar de suas capacidades, as mulheres ainda enfrentam obstáculos para serem aceitas e reconhecidas em áreas onde historicamente os homens predominam. Na Computação, as dificuldades e falta de incentivo refletem no baixo número de mulheres ingressantes nos cursos da área. $\mathrm{O}$ baixo percentual de mulheres nessa área não é só preocupante com relação às tentativas de minimizar as desigualdades dos gêneros, mas também preocupa o mercado de Tecnologia da Informação (TI) atual. Isso porque, de acordo com a IDC, no ano de 2013 houve uma carência de 39,9 mil profissionais de tecnologia e até 2015 esse número 
deveria crescer para 117 mil [INFOEXAME 2013].

Diante desse contexto, nas universidades e no mercado de trabalho existe uma preocupação em criar estratégias de incentivo que visem diminuir essa baixa representatividade das mulheres na Computação [Louzada e outros 2014]. Tais estratégias, de iniciativa pública e privada, utilizam-se de uma significativa variedade de meios para divulgação como blogs, cursos, workshops, mentoring, palestras, oficinas, projetos, entre outros.

O objetivo deste artigo é obter um panorama das iniciativas brasileiras que fomentam a entrada de mulheres da área da Computação. O artigo está organizado da seguinte forma: na Seção 2 descreve-se a metodologia; na Seção 3 analisa-se os dados e na Seção 4 conclui-se o artigo.

\section{Método de Pesquisa}

A busca por iniciativas que estimulem o ingresso de mulheres na área da Computação é um trabalho amplo e não há um método de pesquisa específica para verificar e garantir que todas as iniciativas existentes sejam efetivamente inseridas nessa pesquisa. Assim, os autores deste artigo entenderam que era necessária um método próprio, mas semelhante ao método do Mapeamento Sistemático (MS), proposto por [Petersen e outros 2008] e [Kitchenham 2007].

As etapas executadas foram divididas como apresentadas nas seções a seguir, onde foram definidas (i) as questões de pesquisa e busca das iniciativas; (ii) os critérios de inclusão e exclusão; (iii) a classificação das iniciativas; (iv) e finalmente, a análise destas iniciativas. O mapeamento foi realizado em Agosto de 2014.

\subsection{Questões de pesquisa e busca das iniciativas}

Na primeira etapa do método, questões foram definidas de forma a limitar os dados procurados. As questões de pesquisa definidas foram: (i) Quais e quantas são as iniciativas brasileiras com base nas informações encontradas na web? (ii) Qual o ano de criação das inciativas brasileiras?

Na segunda etapa, utilizaram-se strings de busca para pesquisar essas iniciativas brasileiras por meio de URLs. As strings foram formuladas em inglês e português objetivando mapear as iniciativas brasileiras também redigidas na língua inglesa, visando a internacionalização de tal iniciativa. Como não há uma base de dados científica para os tipos de dados procurados, tal como SCOPUS, IEEE, ACM, SPRINGER, como recomenda o método de Mapeamento Sistemático, optou-se, então, por realizar uma adaptação metodológica e, por conseguinte, recorreu-se à Internet usando como motor de busca o Google, que retorna os resultados mais acessados e populares de acordo com as strings utilizadas. O motor de busca, retornou então, uma quantidade significativa de resultados, mais de 600 milhões. De forma a limitá-los, estipulou-se pelos autores (por conveniência) que os dados seriam procurados nas dez primeiras páginas encontradas. Foram revisadas cem iniciativas com os mesmos termos abaixo, em português e cem em inglês. Com isso, foram selecionados um total de 
duzentos sites. Deve-se ressaltar que as strings aplicadas diretamente no motor de busca Google foram aplicadas aos títulos das páginas e utilizaram a sintaxe a seguir: ((TITLE: woman OR TITLE: women) AND (TITLE: computer)); ((TITLE: woman OR TITLE: women) AND (TITLE: computing)); (( TITLE: woman OR TITLE: women) AND ( TITLE: information technology)); ((mulher OR mulheres) AND (computador))OR ((mulher OR mulheres) AND (Computação))OR ((mulher OR mulheres) AND (tecnologia da informação).

\subsection{Critérios de inclusão e exclusão de dados}

Tendo a relação das URLs encontradas na pesquisa, utilizaram-se critérios de inclusão e exclusão para encontrar os sites com dados relevantes para a pesquisa. Os sites incluídos foram aqueles que se propõem especificamente ao incentivo à mulheres no campo da Computação ou diminuam sua evasão. Já os excluídos, classificados neste artigo como não relevantes, não apresentam propostas de incentivo às mulheres na Computação ou somente mencionam as iniciativas e/ou projetos, como no caso de sites jornalísticos.

\subsection{Classificação de dados}

A partir desses critérios, foi aplicado o critério de classificação dos dados, assim, após análise de inclusão e exclusão, o número de sites foi reduzido. Dos duzentos sites encontrados, no total dezesseis foram de iniciativas brasileiras relevantes (redigido em português ou inglês).

As iniciativas brasileiras encontradas foram:

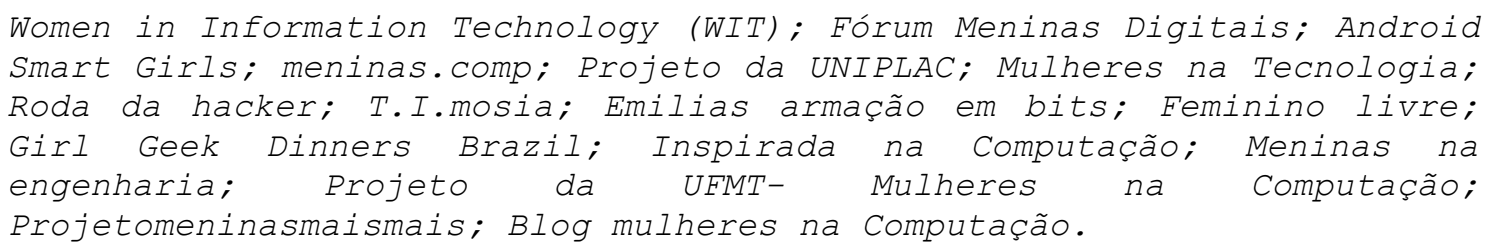

As referências às URLs das iniciativas brasileiras estão disponíveis em: (http://200.17.141.213/ gutanunes/wit2016/apendiceBrasil.pdf).

\section{Análise dos dados}

Muitas das iniciativas pesquisadas utilizam mais de uma fonte de fomento ou patrocinador. Neste contexto, destacam-se as organizações criadas especificamente com o propósito de incentivar mulheres e universidades que desejavam inspirar e aumentar o número de mulheres em seus cursos de Computação. A análise desses dados é apresentada nas subseções seguintes.

\subsection{Catalogação, quantidades e tipos de iniciativa}

De acordo com o método de pesquisa, o primeiro passo foi catalogar título e as URLs 
das respectivas iniciativas. Após essa etapa separaram-se os dados segundo critérios de inclusão e exclusão de iniciativas brasileiras. Após a seleção dos sites que atenderam esses critérios foi possível classificar os dados necessários. Esses dados classificados, ao serem analisados, ajudaram a responder às questões de pesquisa definidas na primeira etapa. O Gráfico 1 apresenta essas classificações obtidas dentre as diversas iniciativas.

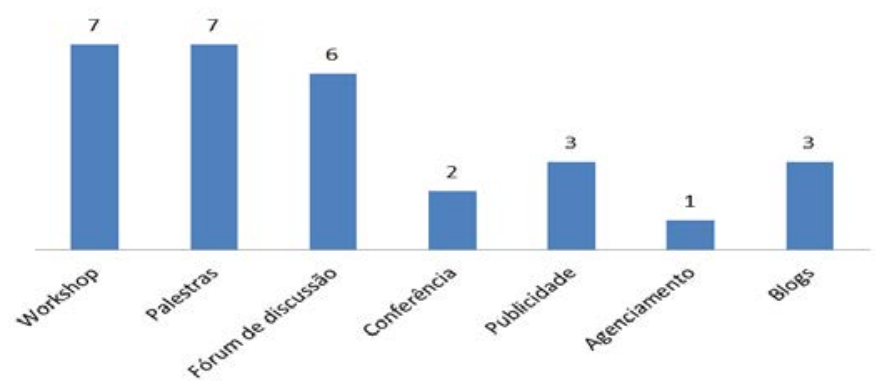

\section{Gráfico 1. Relação entre quantidade e tipos de iniciativas brasileiras}

Analisando o Gráfico 1, verifica-se que no Brasil os workshops e palestras são as iniciativas mais comuns com o intuito de fomentar as mulheres, obtendo sete sites de iniciativas cada um. O agenciamento aparece com um site, sendo o tipo de iniciativa menos utilizada. O caráter mais dinâmico e prático dos workshops e palestras faz que estas sejam estratégias úteis e eficientes para incentivar a entrada de mulheres na área de TI ou mantê-las, no caso de já estarem na área de TI. Os blogs possuem caráter pessoal e são, geralmente, administrados por uma pessoa que deseja informar a respeito de tudo que encontra e sabe sobre o tema em questão. Essa característica dos blogs pode explicar o menor número de sites com esse intuito, já que para incentivar as mulheres é preciso mais que veiculação de informações pela Internet.

\subsection{Ano de criação}

De acordo com a pesquisa verificou-se que existia baixa representatividade em termos quantitativos de sites que apresentassem iniciativas brasileiras específicas para as mulheres na Computação, como pode-se observar no Gráfico 2.

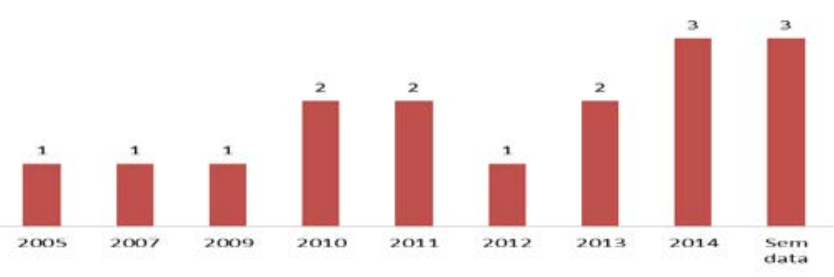

Gráfico 2. Ano de criação das iniciativas brasileiras

De 2005 a 2009 verificou-se que apenas uma iniciativa por ano foi criada. Entre 2010 e 2013 a média de iniciativas criadas aumentou. No ano 2014 observou-se a 
criação de três iniciativas, o maior número encontrado desde o ano de 2005. Do total pesquisado, três iniciativas ou projetos não possuíam data de criação expressa no site, o que impediu sua extração.

\section{Considerações Finais}

Com o uso do método de pesquisa baseado no Mapeamento Sistemático, esse estudo teve como objetivo verificar iniciativas que fomentem a entrada de mulheres na Computação no Brasil. Apesar de ser uma pesquisa limitada devido à grande quantidade de resultados retornados e a não capacidade de lidar com eles na totalidade, tanto pela falta de informações nos sites, como pelo critério que usou-se para definir o limite de páginas efetivamente incluídas, obteve-se, ainda, um mapeamento preliminar das iniciativas brasileiras considerado interessante. Esse mapeamento forneceu uma visão geral das iniciativas existentes para a comunidade acadêmica, de forma que, a partir desse estudo, com o uso das URLs referenciadas, seja possível a extensão de estudos futuros que tratem de outros aspectos mais profundos não tratados nesse artigo. $\mathrm{O}$ baixo número de iniciativas brasileiras encontradas, embora seja representativo na data que a pesquisa foi realizada, pode não apresentar as situação atual das inciativas por limitação do próprio método utilizado no mapeamento e pela data de aplicação. Como trabalho futuro sugere-se o uso de outro método mais adaptado a esse tipo de levantamento estatístico, que reflita precisamente as condições atuais das iniciativas que fomentem a entrada de mulheres na Computação no Brasil.

\section{Agradecimentos}

Ao $\mathrm{MCTI} / \mathrm{CNPq} / \mathrm{SPM}$ pelo fomento ao projeto $\mathrm{N}^{\circ} 420160 / 2013-2$. Ao CNPq pelas bolsas ITI e DT concedidas. À CAPES. À FAPITEC.

\section{Referências}

Kitchenham, B. (2007). Guidelines for performing Systematic Literature Reviews in Software Engineering, Technical Report. Keele University at Staffordshire and University of Durham.UK.

Infoexame (2013). Falta de profissionais de TI se agravará, diz IDC. Caderno: NotíciasCarreira. 19/03/2013. Disponível em: < http://exame.abril.com.br/ >

Lima, M. P. (2013).As mulheres na Ciência da Computação. In:Revista Estudos Feministas. Flórianópolis.

Louzada, C. S.; Gomes, W. F.; Nunes, M. A. S. N.; Salgueiro, E. M.; Andrade, B. T.; Lima, P. S. (2014). Um mapeamento das publicações sobre o ingresso das mulheres na Computação. In: CLEI 2014 - VI Congresso da Mulher Latino-americana na Computação, Montevidéu.

Petersen, K. et al.(2008). Systematic mapping studies in software engineering, ACM. New York. 